ANADOLU, J. of AARI

ISSN: 1300-0225 (Print)

E-ISSN: 2667-6087 (Online)

2019, 29 (1): 39-49

DOI: $10.18615 /$ anadolu. 568803

\title{
Farklı Biçim Zamanlarının Yeşil ve Mor Fesleğen (Ocimum basilicum L.) Tiplerinde bazı Verim ve Kalite Özellikleri Üzerine Etkisi
}

\author{
Çiğdem SÖNMEZ ${ }^{1 *} \quad$ Ayşe Ö̈ge ŞIMSŞEK SOYSAL ${ }^{2} \quad$ Aliye YILDIRIM ${ }^{1}$ \\ Fatma BERBEROGLU ${ }^{I}$ Emine BAYRAM \\ ${ }^{1}$ Ege Üniversitesi Ziraat Fakültesi Tarla Bitkileri Bölümü, Bornova, İzmir/TURKEY \\ ${ }^{2}$ Ordu Üniversitesi Ziraat Fakültesi Tarla Bitkileri Bölümü, Ordu/TURKEY \\ * Corresponding author (Sorumlu yazar): cigdemsnmz@gmail.com \\ Received (Geliş tarihi): 20.06.2018 Accepted (Kabul tarihi): 30.01.2019
}

\begin{abstract}
ÖZ: Bu çalışmada, farklı biçim zamanlarının yeşil ve mor fesleğen (Ocimum basilicum L.) tiplerinde bazı verim ve kalite özelliklerine etkisini belirlemek amaçlanmıştır. Denemeler Ege Üniversitesi Ziraat Fakültesi Tarla Bitkileri Bölümü’nün Bornova/İzmir'de bulunan deneme tarlasında 2013 ve 2014 ylllarl yetiştirme dönemlerinde iki yll süreyle yürütülmüştür. Araştırmada, her iki fesleğen tipinde de ilk hasat, bitkilerin tarlaya şaşırtılmasından 40 gün sonra yapılmıştır ve daha sonra 15 günlük aralarla toplam altı hasat gerçekleştirilmiștir. Çalıșmada bitki boyu ( $\mathrm{cm})$, yeşil herba verimi $\left(\mathrm{kg} \mathrm{da}^{-1}\right)$, drog herba verimi

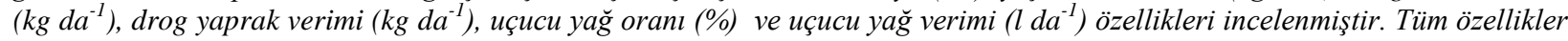
bakımından elde edilen değerler için iki yıl üzerinden birleştirilmiş varyans analizleri yapılmıştır. Varyans analizi sonuçları tüm özellikler bakımından hem populasyon hem de biçim zamanı ortalamaları arasında önemli farklılıkların bulunduğunu göstermiştir. Tüm özelliklere iliş̧kin populasyon x biçim zamanı interaksiyonları önemli bulunurken populasyon $x$ biçim zamanı $x$ yll interaksiyonları ise önemsiz olmuştur. Biçim zamanları bakımından ortalama drog yaprak verimleri ilk yll (2013) 201,25$295,90 \mathrm{~kg} \mathrm{da}{ }^{-1}$, ikinci yl (2014) 221,62-343,91 kg da değerleri arasında ve ortalama uçucu yağ verimleri de ilk yll (2013) 1,352,35 L da ikinci yıl da (2014) 1,43-2,94 L da arasında değişmiştir. En yüksek ortalama değerler yeşil renkli fesleğende ve çoğunlukla 2. biçim zamanında (dikimden itibaren 55 gün sonra), 3. biçim zamanında (dikimden itibaren 70 gün sonra) ve 4. biçim zamanında (dikimden itibaren 85 gün sonra) elde edilirken; en düşük ortamalar ise uçucu yağ oranı dışındaki özellikler yönünden mor fesleğen populasyonunda çoğunlukla 5. biçim zamanında (dikimden itibaren 100 gün sonra) ve 1. biçim zamanında (dikimden itibaren 40 gün sonra)gerçekleşmiştir. Drog herba verimi, drog yaprak verimi ve uçucu yağ verimi bakımından eş zamanlı olarak 2. biçim zamanında (dikimden itibaren 55 gün sonra) ve 4. biçim zamanında (dikimden itibaren 85 gün sonra) yeşil fesleğen populasyonunda yüksek ortalamalar elde edilmiştir. Sonuçta, kıyı Ege Bölgesi koşullarında yapılacak fesleğen üretimlerinde yüksek yaprak ve yă̆ verimleri eldesi için yeşil fesleğenin kullanılması ve hasadın da 2. veya 4. biçim zamanlarında yapılması önerilmiştir.
\end{abstract}

Anahtar Sözcükler: Fesleğen, Ocimum basilicum L., ontogenetik değişkenlik, uçucu yăg.

\section{The Effect of Different Cutting Interval on some Yield and Quality Characteristics of Green and Purple Basils (Ocimum basilicum L.) Types}

\begin{abstract}
In this study, it was aimed to research the effect of different harvest periods on the some yield and quality characteristics of in purple and green sweet basil (Ocimum basilicum L.). The field experiments were conducted in the experimental fields of Department of Field Crops, Faculty of Agriculture, Ege University, Bornova/Izmir in the growing seasons of the 2013 and 2014. In the trials, two genotypes of basil (purple and green) plants were firstly harvested after 40 days from transfering to the field and six different harvesting times were performed with 15 days interval. The plant height (cm), fresh herbage yield $\left(\mathrm{kg} \mathrm{da}^{-1}\right)$, drug herbage yield $\left(\mathrm{kg} \mathrm{da}^{-1}\right)$, drug leaves yield $\left(\mathrm{kg} \mathrm{da}^{-1}\right)$, essential oil content $(\%)$ and essential oil yield
\end{abstract}


$\left(l \mathrm{da}^{-1}\right)$ were determined. For all characteristics, the combined variance analyses were carried out for mean values over two years. Results from variance analyses indicated to be significant differences among means of both harvest intervals and populations for all characteristics studied. The population $x$ harvest times $x$ year interactions were found not to be significant while the population $x$ harvest time interaction were significant for all characteristics. For harvesting intervals, mean drug leaf yields varied between 201.25 and $295.90 \mathrm{~kg} \mathrm{da}^{-1}$ in the first year (2013), 221.62 and $348.91 \mathrm{~kg}^{-1} \mathrm{in}$ the second (2014) year and

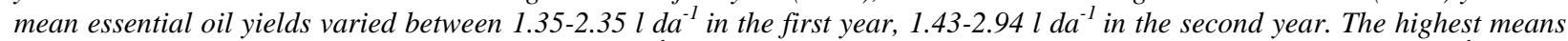
were found in the green population of basil at the $2^{\text {nd }}$ harvest (harvested after 55 days from transfering to the field), $3^{\text {rd }}$ harvest (harvested after 70 days from transfering to the field) and $4^{\text {th }}$ harvest times for all characteristics. The lowest means were mostly obtained from the all characteristics except essential oil content in purple population at the times of $5^{\text {th }}$ harvest (harvested after 100 days from transfering to the field) and $1^{\text {st }}$ harvest (harvested after 40 days from transfering to the field) harvest times. The highest means were simultaneously achieved in the green population of basil at the $2^{\text {nd }}$ harvest (harvested after 55 days from transfering to the field) and $4^{\text {th }}$ harvest (harvested after 85 days from transfering to the field) harvest times for drug herbage yield, drug leaf yield and essential oil yield. As a result, the use of green population of basil and the realizing of harvest at the $2^{\text {nd }}$ harvest (harvested after 55 days from transfering to the field) or $4^{\text {th }}$ harvest (harvested after 85 days from transfering to the field) times were suggested to obtain high yields of drug leaf and essential oil for commercial productions of basil at the coastal Aegean Region.

Keywords: Sweet basil, Ocimum basilicum L., ontogenetic variability, essential oil.

\section{GíRiş}

Ocimum türleri içerisinde ekonomik öneme sahip olan başlıca tür Ocimum basilicum L.'dur. Bitki Lamiaceae familyasına dahil olup orijini Güney Asya özellikle Hindistan'dır. Daha çok tropik ve 1lıman bölgelerde yetiştirilmektedir. Tarımının yapıldığı başlıca ülkeler ise Fransa, İtalya ve İspanya'dır (Ceylan, 1997). Ocimum basilicum L. türünün geniş morfolojik ve kimyasal varyasyona sahip olduğu bilinmekte olup alt tür ve varyetelere ayrılarak incelenmektedir. Ülkemizin doğu bölgelerinde yaygın olarak kullanılan mor renkli tipler "reyhan" adıyla isimlendirilirken, yurt dışında "sweet basil" olarak bilinen yeşil renkli varyetelere ise bat1 bölgelerinde "fesleğen" denmektedir. Gıda, baharat sanayinde, uçucu yağı alkolsüz içeceklerde, firın, şekerlemeler, dondurmalar, sirkeler, et ve çeşni ürünlerinde, ayrıca parfümeri gibi çok çeşitli alanlarda kullanılmaktadır. Uçucu yağ oranının \%0,3-1,0 değerleri arasında değiştiği belirtilmektedir (Akgül, 1993; Telci ve ark., 2005).

Uçucu yă oranı ve bileşimini ontogenetik (bitkinin gelişme dönemi sürecinde etken madde değişimi) varyabilite de etkilemektedir. Ocimum basilicum L. türüne ait bitkilerin morfolojik özelliklerinin yanı sıra uçucu yağ oranı ve bileşiminde de farklılıklar bulunmaktadır. Bu türün içinde var olan çok çeşitlilikten dolayı pek çok ülkede farmasötik, kozmetik ve gıda amaçlı kullanılmak üzere tarımı yapılmaktadır. Fesleğen tiplerinde uçucu yağın başlıca bileşenine göre 18 farklı sınıflandırma olup bunların bazıları; estragol, metil öjanol, linalol, metil sinnamet ya da sineol tipleridir (Telci ve ark., 2005; Nurzynska-Wierdak ve ark., 2012). Uçucu yağ oranı ve bitki yaşı arasında var olan ilişki biyosentez süreçlerinden meydana gelir. Uçucu yağ sentezi, sadece çok genç hücreler tarafindan oluşturulur. Sentez süreçlerinde uçucu yă̆ hücreden dışarı salınır. Yüzde olarak belirtilen yapraktaki uçucu yağ miktarı, bitki gelişiminin yanı sıra, uçucu yağın buharlaşmasıyla da azalmaya başlar. Bu nedenle, kültürü yapılan diğer bitkilerde olduğu gibi, tıbbi ve aromatik bitkiler içerisinde yer alan Ocimum basilicum L.'da da kaliteli ve verimli ürün elde etmek için hasat zamanı büyük önem taşımaktadır. Doğru biçim zamanın belirlenmesi aynı zamanda ham maddenin kimyasal bileşim ve aktivitesinin bozulmaması açısından da önemlidir. Fesleğen uçucu yağı antimikrobiyal, antioksidan ve bazı önemli farmasötik etkilere sahiptir (Sokovic ve ark., 2007; Hussain ve ark., 2008; Koba ve ark., 2009; Chrpova ve ark., 2010).

$\mathrm{Bu}$ çalışmanın amacı, iki farklı fesleğen tipinde önemli bazı verim özellikleri (yeşil herba verimi, drog yaprak verimi vb.) ve kalite kriterlerinden biri olan uçucu yağ verimi üzerinde farklı biçim zamanlarının etkisini belirlemektir. 


\section{MATERYAL ve METOT}

Bu çalışma Ege Üniversitesi Ziraat Fakültesi Tarla Bitkileri Bölümü deneme alanında 2013 ve 2014 yıllarında iki yıl süre ile yürütülmüştür. Araştırmanın yapıldığı yer olan İzmir'de tipik Akdeniz iklimi hüküm sürmekte olup kışları serin ve yağışl1, yazları ise sicak ve kuraktır. Deneme yerine ait toprak özellikleri aşağıda verilmiştir (Çizelge 1). Toprak özellikleri bakımından killi bünyeli, 0-30 $\mathrm{cm}$ derinliğinde 8,2 olan $\mathrm{pH}$ değeri, $30-60 \mathrm{~cm}$ derinliğinde ise $7,8^{\prime}$ dir. Organik madde bakımından fakir olduğu tespit edilmiştir.

Araştırma materyalini oluşturan mor (karanfil kokulu) ve yeşil renkli (limon kokulu) fesleğen tohumları, 1:1:1 oranında elenmiş toprak yanmış ahır gübresi ve elenmiş kumla hazırlanan fidelik harcına 2013 ve 2014 yıllarında Mart ayının ilk haftası ekilmiştir. Düzenli bakım işlemleri yapılıp pişkin fide durumuna gelen fideler ilk y1l 16 Mayıs 2013, ikinci y1l ise 7 Mayıs 2014 tarihinde tarlaya şaşırtılmıştır. Fesleğen fideleri, bölünmüş parseller deneme düzenine göre iki faktörlü ve üç tekrarlamalı olarak tesadüf blokları desenine göre kurulmuş olup dikim normu $40 \times 20 \mathrm{~cm}$ ve parsel büyüklüğü $1,2 \mathrm{~m} \times 3 \mathrm{~m}=3,6 \mathrm{~m}^{2}$, dir. Ana parsellere yerleştirilen mor ve yeşil renkli fesleğen genotiplerinin her biri populasyon niteliğinde olup sırasıyla Malatya ve Tokat ekolojik koşullarından köken almışlardır. Alt parsellere ise biçim zamanları yerleştirilmiştir. Tohumlar Gaziosmanpaşa Üniversitesi Ziraat Fakültesi Tarla Bitkileri Bölümü'nden temin edilmiştir. Yeşil renkli fesleğen limon kokulu iken mor fesleğen karanfil kokuludur. Ontogenetik varyabilitenin araştırıldı ${ }_{1}$ çalışmada altı farklı zamanda biçim yapılmıştır: 1 . Biçim zamanı: dikimden itibaren 40 gün sonra (25
Mayıs 2013-16 Haziran 2014), 2. Biçim zamanı (11 Temmuz 2013-1 Temmuz 2014): dikimden itibaren 55 gün sonra, 3. Biçim zamanı (26 Temmuz 2013-16 Temmuz 2014): dikimden itibaren 70 gün sonra, 4. Biçim zamanı (10 Ağustos 2013-31 Temmuz 2014): dikimden itibaren 85 gün sonra, 5. Biçim zamanı (25 Ağustos 2013-15 Ağustos 2014 ): dikimden itibaren 100 gün sonra ve 6. Biçim zamanı (9 Eylül 2013-31 Ağustos 2014): dikimden itibaren 115 gün sonra biçimler yapılmıştır. Aynı yıl içinde altı biçim zamanında iki kez biçim yapılmış ve bitki boyu ile uçucu yağ oranı dışındaki özelliklerde tüm biçimlerden elde edilen hasat toplamları değerlendirilmiştir.

Aynı yıl içerisinde her parselde ikinci kez biçimlere ise iki ayın sonunda, aynı zaman aralıkları dikkate alınarak hasat işlemi gerçekleştirilmiştir. Araştırmada bitki boyu, yeşil herba verimi, drog herba verimi, drog yaprak verimi, uçucu yağ oranı ve uçucu yağ verimine ilişkin ölçümler aşağıda belirtilen şekilde yapılmıştır.

Bitki boyu (cm): Biçimlerden hemen önce her parselden tesadüfi 10 bitkinin toprak yüzeyinden en uç noktasına kadar yükseklikleri $\mathrm{cm}$ olarak ölçülerek ortalamaları alınmıştır.

Yeşil herba verimi $\left(\mathrm{kg} \mathrm{da}^{-1}\right)$ : Parsellerde kenar tesirleri alındıktan sonra, geriye kalan tüm bitkiler toprak seviyesinden $10 \mathrm{~cm}$ yükseklikte biçilip tartılarak parsel verimleri belirlenmiştir. Elde edilen parsel verimleri $\mathrm{kg} \mathrm{da}^{-1}$ olarak hesaplanmıştır.

Drog herba verimi $\left(\mathbf{k g ~ d a} \mathbf{~}^{-1}\right)$ : Taze herbadan alınmış 500 g'lık örnekler, $35{ }^{\circ} \mathrm{C}$ kurutularak \% nem kaybı belirlenmiş ve bu orandan faydalanarak drog herba verimleri hesaplanmıştır.

Çizelge 1. Deneme alanının bazı fiziksel ve kimyasal toprak özellikleri.

Table 1. Some physical and chemical characteristics of soil at the experimental field.

\begin{tabular}{lccccc}
\hline $\begin{array}{l}\text { Derinlik }(\mathrm{cm}) \\
\text { Depth }(\mathrm{cm})\end{array}$ & $\begin{array}{c}\text { Bünye } \\
\text { Structure }\end{array}$ & $\begin{array}{c}\text { Toplam tuz }(\%) \\
\text { Total salt }(\%)\end{array}$ & $\begin{array}{c}\text { Organik Madde }(\%) \\
\text { Organic Matter }(\%)\end{array}$ & pH & $\begin{array}{c}\text { Kireç }(\%) \\
\text { Lime }(\%)\end{array}$ \\
\hline $0-30$ & Killi/Clayey & 0,095 & 1,130 & 8,2 & 21,52 \\
$30-60$ & Killi /Clayey & 0,075 & 1,150 & 7,8 & 16,64 \\
\hline
\end{tabular}


Drog yaprak verimi $\left(\mathbf{k g ~} \mathbf{d a}^{-1}\right)$ : Taze herbadan alınmış 500 g'lık örnekler, $35{ }^{\circ} \mathrm{C}$ kurutularak elde edilen drog herbadan yaprak ayrımı yapıldıktan sonra drog yaprak verimleri $\mathrm{kg} \mathrm{da}^{-1}$ olarak hesaplanmıştır.

Uçucu yăğ oranı (\%): Uçucu yağ oranları, $35^{\circ} \mathrm{C}$ kurutulmuş drog yaprak örneklerinde ayrı ayrı Neo-Clevenger apereyi ile volümetrik olarak belirlenmiştir. Uçucu yağ oranları hava kurusu üzerinden $\mathrm{ml} / 100$ gram (\%) olarak verilmiştir (Wichtl, 1971).

Uçucu yağ verimi (l da $\left.{ }^{-1}\right)$ : Uçucu yağ oranı ile drog yaprak veriminin çarpılması sonucunda uçucu yağ verimleri $1 \mathrm{da}^{-1}$ olarak hesaplanmıştır.

İstatistiksel değerlendirmelerde TARİST istatistik programı kullanılmıştır. Tüm özelliklere ilişkin değerler için iki yll üzerinden birleştirilmiş varyans analizi yapılmıştır. Muamele ortalamaları arasındaki farkl11ıklar LSD testi ile kontrol edilmiştir (Açıkgöz ve ark., 1994). Y11 x populasyon x biçim zamanı interaksiyonunun önemsiz olduğu özelliklerde populasyon ve biçim zamanı ortalamaları yıllar üzerinden birleştirilmiştir.

\section{BULGULAR ve TARTISMA}

İncelenen her özellik için iki y1l üzerinden birleştirilmiş varyans analizi sonuçları Çizelge 2'de sunulmuştur. Tüm özellikler bakımından hem populasyon hem biçim zamanının önemli etkide bulunduğu görülmektedir. Y1l x populasyon ve yıl $\mathrm{x}$ biçim zamanı interaksiyonları sadece bitki boyu için önemli bulunmuştur. Populasyon ve biçim zamanı etkileri bitki boyu dışındaki özellikler bakımından iki yıl üzerinden tutarlılık gösterirken bitki boyu için yıllar arasında bir farklılık söz konusudur. Tüm özellikler için populasyon x biçim zamanı interaksiyonları önemli bulunmuştur. Buna karşın, $\mathrm{y} 1 \mathrm{x}$ populasyon $\mathrm{x}$ biçim zamanı interaksiyonlarının ise önemsiz olduğu gözlenmiştir. Buna göre populasyonların değişik biçim zamanlarına olan farklı tepkilerinin yıllara göre değişmediğini bir başka deyişle tüm özellikler bakımından populasyon $\mathrm{x}$ biçim zamanı interaksiyonunun tutarlı biçimde ortaya çıktığını söylemek mümkündür.

\section{Bitki boyu}

Biçim zamanları bakımından her iki populasyonda 2013, 2014 yılları ve iki y1l üzerinden elde edilmiş ortalama değerler Çizelge 3'de verilmiștir. Çalışmada 2014 yılına ilişkin bitki boyu ortalaması $(61,52 \mathrm{~cm})$ bir önceki yıla göre daha yüksek $(55,40$ $\mathrm{cm})$ olmuştur. Bitkinin büyüme ve gelişme oluşturan Mayıs ile Eylül ayları arasındaki dönemde 2013 y1lında toplam yağış miktarı 96,10 mm iken aynı dönemde 2014 yılında ise bu miktar 206,10 mm olarak kaydedilmiştir. Bu olgunun ikinci yıldaki bitki boyu yüksekliğinin nedeni olduğu söylenebilir. Biçim zamanları bakımından populasyonlarda iki yıl üzerinden elde edilmiş ortalama değerler Çizelge 3'te verilmiştir. Populasyon x biçim zamanı interaksiyonu önemli bulunmuştur (Çizelge 3). En yüksek bitki boyu ortalaması yeşil fesleğen için dördüncü biçim zamanında elde edilirken $(76,73 \mathrm{~cm})$ en düşük değer de mor fesleğenin birinci biçiminde $(34,55$ $\mathrm{cm}$ ) belirlenmiștir. Tüm biçim zamanlarında yeșil fesleğen populasyonunun bitki boyu diğer populasyondan daha yüksek bulunmuştur. Ancak bu üstünlük biçim zamanlarına göre farklı düzeylerde gerçekleşmiştir.

Telci ve ark. (2005), Türkiye'de yapılan yerel fesleğen populasyonlarının morfolojik, agronomik ve teknolojik özelliklerinin karakterizasyonu ve üstün bitkilerin seleksiyonuna yönelik çalıșmalarında limon kokulu fesleğenlerde bitki boyunun 70,00$90,00 \mathrm{~cm}$, mor fesleğenlerde ise $30,00-47,40 \mathrm{~cm}$ arasında değiştiğini belirtmişlerdir. Verma ve ark. (2012), Hindistan koşullarında fesleğen bitkisinde ontogenetik varyabilitenin etkisini araștırmışlar ve bitki boyu değerlerinin $44,60 \mathrm{~cm}$ ile $94,60 \mathrm{~cm}$ arasında değiştiğini belirtmişlerdir. NurzynskaWierdak ve ark. (2012), ise fesleğen bitkisinin farklı gelişme dönemlerindeki uçucu yağ oranlarını inceledikleri çalışmalarında bitki boyunu 56,30$59,60 \mathrm{~cm}$ arasında bulmuşlardır. Aslan (2014), farklı reyhan (Ocimum basilicum L.) populasyonlarında ontogenetik ve morfogenetik varyabilitenin etkilerini belirlemeye çalışmış, bitki boyu değerlerinin 37,64-95,00 cm olduğunu bildirmiştir. Bornova koşullarında yürütülen bu çalışma sonuçlarına göre genel olarak elde edilen değerler Nurzynska-Wierdak ve ark. (2012) sonuçlarından yüksek iken Verma ve ark. (2012) 
ve Aslan (2014)'ın değerleri arasında bulunmuştur. Telci ve ark. (2005)'nın bulguları ile çalışmamızın bitki boyu değerleri karşılaştırıldığında mor renkli fesleğenlerin araştırıcıların değerlerinden biraz daha yüksek, limon kokulu olanların ise daha düşük olduğu saptanmıştır. İncelenen iki populasyon arasında bitki boyu değerleri bakımından farklılığın bulunduğu ve yeşil renkli (limon kokulu) fesleğenlerin daha boylu oldukları gözlemlenmiştir.

\section{Yeşil herba verimi}

Biçim zamanları bakımından her iki populasyonda 2013, 2014 y1lları ve iki yıl üzerinden elde edilmiş ortalama değerler Çizelge 4'de verilmiştir. Çalışmada
2014 y1lına ilișin yeșil herba verimi ortalaması $\left(1848,20 \mathrm{~kg} \mathrm{da}^{-1}\right)$ bir önceki yıla göre daha yüksek $\left(1654,46 \mathrm{~kg} \mathrm{da}^{-1}\right)$ olmuştur. Populasyon x biçim zamanı interaksiyonu önemli bulunmuştur (Çizelge 4). En yüksek yeșil herba verimi üçüncü biçim zamanında yeşil fesleğenden $\left(2641,48 \mathrm{~kg} \mathrm{da}^{-1}\right)$ elde edilirken beşinci ve altıncı biçim zamanlarında mor renkli fesleğen populasyonu (1046,32 ve 1175,17 $\mathrm{kg} \mathrm{da}^{-1}$ ) sahip olmuştur. Tüm biçim zamanlarında yeşil fesleğen populasyonunun yeşil herba verimi diğer populasyondan daha yüksek bulunmuştur. Ancak bu üstünlük biçim zamanlarına göre farklı düzeylerde gerçekleşmiştir.

Çizelge 2. İncelenen özelliklere ilișkin varyans analizinden elde edilen kareler ortalamaları.

Tablo 2. Mean squares obtained from analysis of variance for characteristics studied.

\begin{tabular}{|c|c|c|c|c|c|c|c|}
\hline $\begin{array}{l}\text { Varyasyon Kaynağı } \\
\text { Sources of variability }\end{array}$ & $\begin{array}{c}\text { Serbestlik } \\
\text { Derecesi } \\
\text { DF }\end{array}$ & $\begin{array}{l}\text { Bitki boyu } \\
\text { Plant height }\end{array}$ & $\begin{array}{c}\text { Yeşil Herba } \\
\text { Verimi } \\
\text { Fresh herbage } \\
\text { yield }\end{array}$ & $\begin{array}{c}\text { Drog Herba } \\
\text { Verimi } \\
\text { Drug herbage } \\
\text { yield }\end{array}$ & $\begin{array}{c}\text { Drog Yaprak } \\
\text { Verimi } \\
\text { Drug leaf } \\
\text { yield }\end{array}$ & $\begin{array}{c}\text { Uçucu Yağ } \\
\text { Oranı } \\
\text { Essential } \\
\text { oil content }\end{array}$ & $\begin{array}{c}\text { Uçucu Yağ } \\
\text { Verimi } \\
\text { Essential oil } \\
\text { yield }\end{array}$ \\
\hline Y1l (Year) & 1 & $829,60 * *$ & $1188781,71 * *$ & 3061,14 & $77886,15^{* *}$ & $0,081 *$ & $0,82 * *$ \\
\hline Populasyon (Population) & 1 & $5161,28 * *$ & $11409936,16 * *$ & $541245,56^{* *}$ & $157762,81 * *$ & $0,161 * *$ & $15,74 * *$ \\
\hline Yil X Populasyon & 1 & $1130,50 * *$ & 69910,39 & 15869,01 & 3357,90 & 0,002 & 0,46 \\
\hline Biçim zamanı (Cutting intervals) & 5 & $982,12 * *$ & $688966,30^{* *}$ & $53195,70 * *$ & $19028,20^{* *}$ & $0,094 * *$ & $2,06^{* *}$ \\
\hline Yıl X Biçim zamanı & 5 & $622,79 * *$ & 62616,98 & 5557,26 & 1360,40 & 0,005 & 0,17 \\
\hline Populasyon X Biçim zamanı & 5 & $41,96^{*}$ & $281559,33^{*}$ & $25073,90 *$ & $21482,18^{* *}$ & $0,230 * *$ & $1,19 * *$ \\
\hline Yıl X Populasyon X Biçim zamanı & 5 & 13,00 & 35683,43 & 6803,69 & 2259,35 & 0,004 & 0,23 \\
\hline Hata & 44 & 16,96 & 103466,72 & 7514,76 & 3240,86 & 0,018 & 0,30 \\
\hline $\mathrm{CV}(\%)$ & & 0,60 & 19,60 & 21,40 & 20,80 & 17,88 & 27,20 \\
\hline
\end{tabular}

*, **: $\mathrm{P} \leq 0,05$ ve $\mathrm{P} \leq 0,01$ düzeyinde önemli / *, **: Significant at $\mathrm{P} \leq 0.05$ and $\mathrm{P} \leq 0.01$.

Çizelge 3. Fesleğen tiplerinde bitki boylarının $(\mathrm{cm})$ biçimlere ve yıllara göre değişimi (2013-2014).

Table 3. Change of plant height $(\mathrm{cm})$ in basil types according to cutting times and years (2013-2014).

\begin{tabular}{|c|c|c|c|c|c|c|c|c|c|}
\hline \multirow{3}{*}{$\begin{array}{l}\text { Biçim } \\
\text { zamanları } \\
\text { Cutting } \\
\text { times }\end{array}$} & \multicolumn{9}{|c|}{ Bitki boyu $(\mathrm{cm}) /$ Plant height $(\mathrm{cm})$} \\
\hline & \multicolumn{3}{|c|}{$\begin{array}{c}\text { 1. Y11 / } 1^{\text {st }} \text { year } \\
2013\end{array}$} & \multicolumn{3}{|c|}{$\begin{array}{l}\text { 2. Y1l / } 2^{\text {nd }} \text { year } \\
2014\end{array}$} & \multicolumn{3}{|c|}{$\begin{array}{c}\text { Genel ortalama / General mean } \\
2013-2014\end{array}$} \\
\hline & $\begin{array}{c}\text { Mor } \\
\text { Purple }\end{array}$ & $\begin{array}{l}\text { Yeşil } \\
\text { Green }\end{array}$ & $\begin{array}{l}\text { Ort. } \\
\text { Mean }\end{array}$ & $\begin{array}{c}\text { Mor } \\
\text { Purple }\end{array}$ & $\begin{array}{l}\text { Yeşil } \\
\text { Green }\end{array}$ & $\begin{array}{l}\text { Ort. } \\
\text { Mean }\end{array}$ & $\begin{array}{l}\text { Mor } \\
\text { Purple }\end{array}$ & $\begin{array}{l}\text { Yeşil } \\
\text { Green }\end{array}$ & $\begin{array}{l}\text { Ort. } \\
\text { Mean }\end{array}$ \\
\hline 1 & $40,27^{\mathrm{e}}$ & $58,55^{\mathrm{bc}}$ & $49,41^{\mathrm{c}}$ & 28,83 & 38,69 & $33,76^{\mathrm{d}}$ & $34,55^{\mathrm{g}}$ & $48,62^{\mathrm{f}}$ & $41,58^{\mathrm{c}}$ \\
\hline 2 & $48,70^{\mathrm{d}}$ & $70,22^{\mathrm{ab}}$ & $59,46^{\mathrm{ab}}$ & 61,52 & 67,65 & $64,59^{\mathrm{bc}}$ & $55,11^{\text {cde }}$ & $68,93^{\mathrm{b}}$ & $62,02^{\mathrm{b}}$ \\
\hline 3 & $46,78^{\mathrm{d}}$ & $75,07^{\mathrm{a}}$ & $60,93^{\mathrm{a}}$ & 54,92 & 64,73 & $59,83^{\mathrm{c}}$ & $50,85^{\text {def }}$ & $69,90^{\mathrm{b}}$ & $60,38^{\mathrm{b}}$ \\
\hline 4 & $44,27^{\mathrm{de}}$ & $75,53^{\mathrm{a}}$ & $59,90^{\mathrm{ab}}$ & 58,10 & 77,94 & $68,02^{\mathrm{ab}}$ & $51,19^{\mathrm{c}}$ & $76,73^{\mathrm{a}}$ & $63,96^{\mathrm{a}}$ \\
\hline 5 & $40,28^{\mathrm{e}}$ & $64,15^{\mathrm{bc}}$ & $52,21^{\mathrm{c}}$ & 58,18 & 78,85 & $68,51^{\mathrm{a}}$ & $49,23^{\text {ef }}$ & $71,50^{\mathrm{ab}}$ & $60,36^{\mathrm{b}}$ \\
\hline 6 & $40,06^{\mathrm{e}}$ & $60,95^{\mathrm{bc}}$ & $50,51^{\mathrm{c}}$ & 73,05 & 75,70 & $74,38^{\mathrm{a}}$ & $56,56^{\mathrm{cd}}$ & $68,32^{\mathrm{b}}$ & $62,44^{\mathrm{ab}}$ \\
\hline $\begin{array}{l}\text { Ort./ } \\
\text { Mean }\end{array}$ & $43,39^{\mathrm{b}}$ & $67,41^{\mathrm{a}}$ & $55,40^{\mathrm{b}}$ & 55,77 & 67,26 & $61,52^{\mathrm{a}}$ & $49,58^{b}$ & $67,33^{\mathrm{a}}$ & 58,45 \\
\hline LSD & \multicolumn{3}{|c|}{$\begin{array}{l}\text { Populasyon }(\mathrm{P} \leq 0,01): 6,75 \\
\text { Biçim zamanı }(\mathrm{P} \leq 0,01): 4,56 \\
\text { Populasyon x biçim zamanı }(\mathrm{P} \leq 0,05): 6,25\end{array}$} & \multicolumn{3}{|c|}{ Biçim zamanı $(\mathrm{P} \leq 0,01): 7,49$} & \multicolumn{3}{|c|}{$\begin{array}{l}\text { Populasyon }(\mathrm{P} \leq 0,01): 10,28 \\
\text { Biçim zamanı }(\mathrm{P} \leq 0,01): 4,55 \\
\text { Populasyon x biçim zamanı }(\mathrm{P} \leq 0,05): 6,42 \\
\text { Y1l }(\mathrm{P} \leq 0,01): 2,61\end{array}$} \\
\hline $\mathrm{CV}(\%)$ & \multicolumn{3}{|c|}{4,80} & & 6,30 & & & 0,6 & \\
\hline
\end{tabular}

Aynı harfle gösterilen ortalamalar arasında önemli fark ( $\mathrm{P} \leq 0,05$ ve $\mathrm{P} \leq 0,01)$ yoktur.

There is no significant difference $(\mathrm{P} \leq 0.05$ and $(\mathrm{P} \leq 0.01)$ among means indicated by same letter. 
Çizelge 4. Fesleğen tiplerinde yeşil herba veriminin $\left(\mathrm{kg} \mathrm{da}^{-1}\right)$ biçimlere ve y1llara göre değişimi (2013-2014).

Table 4. Change of fresh herbage yield $\left(\mathrm{kg} \mathrm{da}^{-1}\right)$ in basil types according to cutting times and years (2013-2014).

\begin{tabular}{|c|c|c|c|c|c|c|c|c|c|}
\hline \multirow{3}{*}{$\begin{array}{l}\text { Biçim } \\
\text { zamanları } \\
\text { Cutting } \\
\text { times }\end{array}$} & \multicolumn{9}{|c|}{ Yeşil herba verimi $\left(\mathrm{kg} \mathrm{da}^{-1}\right) /$ Fresh drug herbage yield yield $\left(\mathrm{kg} \mathrm{da}^{-1}\right)$} \\
\hline & \multicolumn{3}{|c|}{$\begin{array}{c}\text { 1. Y1l / } 1^{\text {st }} \text { year } \\
2013\end{array}$} & \multicolumn{3}{|c|}{$\begin{array}{c}\text { 2. Y11 / } 2^{\text {nd }} \text { year } \\
2014\end{array}$} & \multicolumn{3}{|c|}{$\begin{array}{c}\text { Genel ortalama / General mean } \\
2013-2014\end{array}$} \\
\hline & $\begin{array}{l}\text { Mor } \\
\text { Purple }\end{array}$ & $\begin{array}{l}\text { Yeşil } \\
\text { Green }\end{array}$ & $\begin{array}{l}\text { Ort. } \\
\text { Mean }\end{array}$ & $\begin{array}{l}\text { Mor } \\
\text { Purple }\end{array}$ & $\begin{array}{l}\text { Yeşil } \\
\text { Green }\end{array}$ & $\begin{array}{l}\text { Ort. } \\
\text { Mean }\end{array}$ & $\begin{array}{l}\text { Mor } \\
\text { Purple }\end{array}$ & $\begin{array}{l}\text { Yeşil } \\
\text { Green }\end{array}$ & $\begin{array}{l}\text { Ort. } \\
\text { Mean }\end{array}$ \\
\hline 1 & 1310,00 & 1804,90 & $1557,45^{\mathrm{b}}$ & $1389,59^{\mathrm{fg}}$ & $1575,73^{\mathrm{cd}}$ & $1482,66^{\mathrm{c}}$ & $1349,80^{\mathrm{egf}}$ & $1690,32^{\text {cdef }}$ & $1520,06^{\mathrm{c}}$ \\
\hline 2 & 1608,50 & 2005,10 & $1806,80^{\mathrm{ab}}$ & $1860,94^{\text {de }}$ & $2417,71^{\mathrm{ab}}$ & $2139,33^{\mathrm{a}}$ & $1734,72^{\text {bcde }}$ & $2211,41^{\mathrm{ab}}$ & $1973,06^{\mathrm{ab}}$ \\
\hline 3 & 1537,20 & 2624,10 & $2080,65^{\mathrm{a}}$ & $1630,21^{\mathrm{ef}}$ & $2658,86^{\mathrm{a}}$ & $2144,54^{\mathrm{a}}$ & $1583,71^{\text {defg }}$ & $2641,48^{\mathrm{a}}$ & $2112,59^{\mathrm{a}}$ \\
\hline 4 & 952,80 & 1993,55 & $1473,18^{\mathrm{b}}$ & $1506,77^{\mathrm{f}}$ & $2390,63^{\mathrm{ab}}$ & $1948,70^{\mathrm{ab}}$ & $1229,79^{\mathrm{fg}}$ & $2192,09^{\mathrm{b}}$ & $1710,94^{\mathrm{bc}}$ \\
\hline 5 & 964,50 & 1945,70 & $1455,10^{\mathrm{b}}$ & $1128,13^{\mathrm{g}}$ & $2169,27^{\mathrm{bcd}}$ & $1648,70^{c}$ & $1046,32^{\mathrm{h}}$ & $2057,49^{\mathrm{bc}}$ & $1551,90^{\mathrm{c}}$ \\
\hline 6 & 1149,80 & 1957,40 & $1553,60^{\mathrm{b}}$ & $1200,53^{\mathrm{g}}$ & $2250,00^{\mathrm{bc}}$ & $1725,27^{\mathrm{bc}}$ & $1175,17^{\mathrm{gh}}$ & $2103,70^{\mathrm{b}}$ & $1639,43^{b c}$ \\
\hline $\begin{array}{l}\text { Ort./ } \\
\text { Mean }\end{array}$ & $1253,80^{\mathrm{b}}$ & $2055,13^{\mathrm{a}}$ & $1654,46^{\mathrm{b}}$ & $1452,70^{\mathrm{b}}$ & $2243,70^{\mathrm{a}}$ & $1848,20^{\mathrm{a}}$ & $1353,25^{\mathrm{b}}$ & $2149,41^{\mathrm{a}}$ & 1751,33 \\
\hline LSD & \multicolumn{3}{|c|}{$\begin{array}{l}\text { Populasyon }(\mathrm{P} \leq 0,05): 373,96 \\
\text { Biçim zamanı }(\mathrm{P} \leq 0,005): 425,99\end{array}$} & \multicolumn{3}{|c|}{$\begin{array}{l}\text { Populasyon }(\mathrm{P} \leq 0,05): 585,12 \\
\text { Biçim zamanı }(\mathrm{P} \leq 0,01): 256,53 \\
\text { Populasyon x biçim zamanı }(\mathrm{P} \leq 0,05) \text { : } \\
444,96\end{array}$} & \multicolumn{3}{|c|}{$\begin{array}{l}\text { Populasyon }(\mathrm{P} \leq 0,01): 227,65 \\
\text { Biçim zamanı }(\mathrm{P} \leq 0,01): 354,30 \\
\text { Populasyon x biçim zamanı }(\mathrm{p} \leq 0,05) \text { : } \\
\text { 501,05 } \\
\text { Y11 (P } \leq 0,01): 204,00\end{array}$} \\
\hline CV (\%) & \multicolumn{3}{|l|}{15,75} & \multicolumn{3}{|l|}{6,51} & \multicolumn{3}{|l|}{19,60} \\
\hline
\end{tabular}

Aynı harfle gösterilen ortalamalar arasında önemli fark ( $\mathrm{P} \leq 0,05$ ve $\mathrm{P} \leq 0,01)$ yoktur.

There is no significant difference $(\mathrm{P} \leq 0.05$ and $(\mathrm{P} \leq 0.01)$ among means indicated by same letter.

Telci ve ark. (2005), yeşil herba verimlerinin ilk yıl $1609,10 \mathrm{~kg} \mathrm{da}^{-1}$ ile $4706,60 \mathrm{~kg} \mathrm{da}^{-1}$, ikinci yll ise $2935,00 \mathrm{~kg} \mathrm{da}^{-1}$ ile 5345,80 $\mathrm{kg} \mathrm{da}^{-1}$; Erşahin (2006), Diyarbakır ekolojik koşullarında yetiştirilen fesleğen populasyonlarında 1719,20-4450,00 $\mathrm{kg} \quad \mathrm{da}^{-1}$ değerleri arasında değiştiğini bildirmişlerdir. Ekren ve ark. (2009), limon kokulu fesleğende farklı dikim sıklıklarının verim ve kalite özelliklerine olan etkilerini inceledikleri çalışmalarında genel olarak yeşil herba verimlerinin $568,90-3901,20 \mathrm{~kg} \mathrm{da}^{-1}$ arasında değiştiğini saptamışlardır. Aslan (2014) farklı fesleğen populasyonlarında Aydın lokasyonunda yürüttüğü araştırmasında, yeşil herba veriminin ortalama olarak 795,31-3576,76 $\mathrm{kg} \mathrm{da}^{-1}$ değerleri arasında değişim gösterdiğini bildirmiştir. Bornova'da 2013 ve 2014 yıllarında yapilan çalışmamızın yeşil herba verimlerine ilişkin bulguları, Telci ve ark. (2005), Erşahin (2006), Ekren ve ark. (2009) ve Aslan (2014)'ın sonuçları arasında yer almıştır.

Bununla beraber, değerlerimiz araştırıcıların belirttiği en yüksek değerlerden daha düşük bulunmuştur. $\mathrm{Bu}$ durumun bölgenin ekolojik koşullarının ve kullanılan bitki materyalinin farklı olmasından kaynaklanabileceği söylenebilir. Mor renkli fesleğenin yeşil renkli olana göre habitusunun daha zayıf geliştiği gözlemlenmiştir.

\section{Drog herba verimi}

Biçim zamanları bakımından her iki populasyonda 2013, 2014 yılları ve iki y1l üzerinden elde edilmiş ortalama değerler Çizelge 5'de verilmiştir. $\mathrm{Bu}$ özellik bakımından iki yıla ilişkin ortalama değerler arasında önemli bir fark bulunmamıştır. Populasyon $\mathrm{x}$ biçim zamanı interaksiyonu önemli bulunmuştur (Çizelge 5). Yeşil renkli fesleğen populasyonunda birinci biçim zamanı dışındaki tüm biçimlerde 504,62 ile 590,48 $\mathrm{kg} \mathrm{da}^{-1}$ değişen ve aynı istatistik grupta yer alan yüksek ortalamalar elde edilmiştir. Buna karşın en düşük herba verimi ise beşinci ve birinci biçim zamanlarında mor renkli fesleğende (sirasiyla $259,30 \mathrm{~kg} \mathrm{da}^{-1}$ ve $263,87 \mathrm{~kg} \mathrm{da}^{-1}$ ) tespit edilmiştir. Birinci ve ikinci biçim zamanında iki populasyonun drog herba verimleri arasındaki fark önemsiz iken diğer biçim zamanlarında yeşil renkli populasyonun drog herba veriminin mor fesleğen populasyonundan önemli düzeyde daha yüksek olduğu gözlenmiştir. 
C. SÖNMEZ, A. Ö. SIMSSEK SOYSAL, A. YILDIRIM, F. BERBEROĞLU, E. BAYRAM: FARKLI BİĊM ZAMANLARININ YEŞIL VE MOR FESLEĞEN (Ocimum basilicum L.) TIPLERINDDE BAZI VERIM VE KALITE ÖZELLIKLERI ÜZERINE ETKISİ

Çizelge 5. Fesleğen tiplerinde drog herba veriminin $\left(\mathrm{kg} \mathrm{da}^{-1}\right)$ biçimlere ve yıllara göre değişimi (2013-2014).

Table 5. Change of drug herbage yield $\left(\mathrm{kg} \mathrm{da}^{-1}\right)$ in basil types according to cutting times and years (2013-2014).

\begin{tabular}{|c|c|c|c|c|c|c|c|c|c|}
\hline \multirow{3}{*}{$\begin{array}{l}\text { Biçim } \\
\text { zamanları } \\
\text { Cutting } \\
\text { times }\end{array}$} & \multicolumn{9}{|c|}{ Drog herba verimi $\left(\mathrm{kg} \mathrm{da}^{-1}\right) /$ Drug herbage yield $\left(\mathrm{kg} \mathrm{da}^{-1}\right)$} \\
\hline & \multicolumn{3}{|c|}{$\begin{array}{c}\text { 1. Y1l / } 1^{\text {st }} \text { year } \\
2013\end{array}$} & \multicolumn{3}{|c|}{$\begin{array}{l}\text { 2. Y1l / } 2^{\text {nd }} \text { year } \\
2014\end{array}$} & \multicolumn{3}{|c|}{$\begin{array}{l}\text { Genel ortalama / General mean } \\
\text { 2013-2014 }\end{array}$} \\
\hline & $\begin{array}{l}\text { Mor } \\
\text { Purple }\end{array}$ & $\begin{array}{l}\text { Yeşil } \\
\text { Green }\end{array}$ & $\begin{array}{l}\text { Ort. } \\
\text { Mean }\end{array}$ & $\begin{array}{l}\text { Mor } \\
\text { Purple }\end{array}$ & $\begin{array}{l}\text { Yeşil } \\
\text { Green }\end{array}$ & $\begin{array}{l}\text { Ort. } \\
\text { Mean }\end{array}$ & $\begin{array}{l}\text { Mor } \\
\text { Purple }\end{array}$ & $\begin{array}{l}\text { Yeşil } \\
\text { Green }\end{array}$ & $\begin{array}{l}\text { Ort. } \\
\text { Mean }\end{array}$ \\
\hline 1 & 299,60 & 291,30 & $295,45^{\mathrm{b}}$ & 228,23 & 306,87 & $267,55^{\mathrm{d}}$ & $263,87^{\text {cd }}$ & $299,46^{\text {cd }}$ & $281,67^{b}$ \\
\hline 2 & 491,40 & 446,00 & $468,70^{\mathrm{a}}$ & 300,00 & 562,00 & $430,72^{\mathrm{ab}}$ & $396,31^{\mathrm{bc}}$ & $504,62^{\mathrm{ab}}$ & $450,47^{\mathrm{a}}$ \\
\hline 3 & 400,20 & 538,40 & $469,30^{\mathrm{a}}$ & 329,35 & 483,84 & $406,60^{\mathrm{ab}}$ & $364,19^{\text {cd }}$ & $511,74^{\mathrm{ab}}$ & $437,97^{\mathrm{a}}$ \\
\hline 4 & 340,80 & 519,60 & $430,20^{\mathrm{a}}$ & 231,89 & 519,57 & $375,73^{b c}$ & $285,69^{\mathrm{cd}}$ & $519,73^{\mathrm{ab}}$ & $402,71^{\mathrm{a}}$ \\
\hline 5 & 327,00 & 528,30 & $427,65^{\mathrm{a}}$ & 193,11 & 518,22 & $355,67^{b c}$ & $259,30^{\mathrm{d}}$ & $523,43^{\mathrm{ab}}$ & $391,37^{\mathrm{a}}$ \\
\hline 6 & 369,50 & 597,00 & $483,25^{\mathrm{a}}$ & 309,99 & 582,78 & $446,39^{\mathrm{a}}$ & $339,69^{\text {cd }}$ & $590,48^{\mathrm{a}}$ & $465,09^{\mathrm{a}}$ \\
\hline $\begin{array}{l}\text { Ort./ } \\
\text { Mean }\end{array}$ & $371,42^{b}$ & $486,77^{\mathrm{a}}$ & 429,09 & $265,43^{b}$ & $495,58^{\mathrm{a}}$ & 380,48 & $318,16^{\mathrm{b}}$ & $491,58^{\mathrm{a}}$ & 404,87 \\
\hline LSD & \multicolumn{3}{|c|}{$\begin{array}{l}\text { Populasyon }(\mathrm{P} \leq 0,05): 49,54 \\
\text { Biçim zamanı }(\mathrm{P} \leq 0,05): 117,90\end{array}$} & \multicolumn{3}{|c|}{$\begin{array}{l}\text { Populasyon ( }(\mathrm{P} \leq 0,05): 82,59 \\
\text { Biçim zamanı }(\mathrm{P} \leq 0,01): 69,84\end{array}$} & \multicolumn{3}{|c|}{$\begin{array}{l}\text { Populasyon }(\mathrm{P} \leq 0,01): 89,68 \\
\text { Biçim zamanı }(\mathrm{P} \leq 0,01): 95,48 \\
\text { Populasyon x biçim zamanı } \\
(\mathrm{P} \leq 0,05): 135,03\end{array}$} \\
\hline $\mathrm{CV}(\%)$ & \multicolumn{3}{|c|}{7,80} & \multicolumn{3}{|c|}{7,60} & \multicolumn{3}{|c|}{21,40} \\
\hline
\end{tabular}

Aynı harfle gösterilen ortalamalar arasında önemli fark $(\mathrm{P} \leq 0,05$ ve $\mathrm{P} \leq 0,01)$ yoktur.

There is no significant difference $(\mathrm{P} \leq 0.05$ and $\mathrm{P} \leq 0.01)$ among means indicated by same letter.

Telci ve ark. (2005) ülkemizde üretimi yapılan fesleğenlerde drog herba verimini $255,70-712,70$ $\mathrm{kg} \mathrm{da}^{-1}$, Ekren ve ark. (2009) ise 92,00-942,10 kg $\mathrm{da}^{-1}$ olarak bildirmişlerdir. Ekren ve ark. (2012) mor fesleğenlerde farklı su uygulamalarında drog yaprak verimini en düşük141,50 $\mathrm{kg} \mathrm{da}^{-1}$, en yüksek ise $467,70 \mathrm{~kg} \mathrm{da}^{-1}$ olarak saptamışlardır. Aslan (2014) Aydın lokasyonunda farklı kökenli fesleğenlerde ontogenetik varyabiliteyi araştırdığ 1 çalışmasında ortalama drog herba veriminin 237,13 $\mathrm{kg} \mathrm{da}^{-1}$ ile $1225,02 \mathrm{~kg} \mathrm{da}^{-1}$ arasında değiştiğini belirtmiştir. Bornova ekolojik koşullarında 2013 ve 2014 yıllarında yürütülen araştırma sonuçlarımız genel olarak Telci ve ark. (2005), Ekren ve ark. (2009), Ekren ve ark. (2012) ve Aslan (2014)'in belirttiği değerler içerisinde yer almasına rağmen araştırıcıların bildirmiş oldukları en yüksek değerlerin altında bulunmuştur. Fesleğen bitkisi tek yıllık ve yılda birden fazla biçim yapılan bir bitki olup sözü edilen çalışmalarda bitki habitusunun geliştiği her durumda çok sayıda biçim yapılmıştır. Yürüttügümüz çalışmadan farklı olarak, araştırıcılar fesleğen bitkisinde farklı biçim zamanlarında meydana gelen verim değişimlerini incelememişlerdir.

\section{Drog yaprak verimi}

Biçim zamanları bakımından her iki populasyonda 2013, 2014 yılları ve iki yıl üzerinden elde edilmiş ortalama değerler Çizelge 6'da verilmiştir. Çalışmada 2014 yılına ilişskin drog yaprak verimi ortalamas1 $\left(298,00 \mathrm{~kg} \mathrm{da}^{-1}\right)$ bir önceki y1la göre daha yüksek $\left(247,05 \mathrm{~kg} \mathrm{da}^{-1}\right)$ olmuştur. Populasyon $\mathrm{x}$ biçim zamanı interaksiyonu önemli bulunmuştur (Çizelge 6).

Drog yaprak verimi bakımından en yüksek ortalama $371,73 \mathrm{~kg} \mathrm{da}^{-1}$ ile yeşil fesleğenin beşinci biçim zamanında elde edilmiş ancak bu populasyonda birinci biçim zamanı dışındaki diğer ortalamaların da beşinci biçim zamanı ile aynı istatistiksel grupta yer aldığı gözlenmiştir. En düşük drog yaprak verimi ise mor renkli populasyonun beşinci biçim zamanında ortaya çıkmıştır. İlk üç biçim zamanında iki populasyonun ortalamaları arasındaki farklar önemsiz iken diğer biçim zamanlarında (4., 5. ve 6.) yeşil fesleğen diğerine göre önemli düzeyde yüksek ortalamalara sahip olmuştur.

Telci ve ark. (2005)'na göre; Türkiye'de kültürü yapılan fesleğenlerin drog yaprak verimleri 143,60-425,00 kg da ${ }^{-1}$, Ekren ve ark. (2009)'na göre ise 72,50-608,40 $\mathrm{kg} \mathrm{da}^{-1}$ arasında yer almıştır. Ekren ve ark. (2012) farklı su dozu uygulamalarında drog yaprak verimini $112,77 \mathrm{~kg} \mathrm{da}^{-1}$ ile $308,00 \mathrm{~kg}$ $\mathrm{da}^{-1}$ değerleri arasında bulmuşlardır. Aslan (2014) ise Aydın ekolojik koşullarında, ortalama drog yaprak verimini $97,92-542,42 \mathrm{~kg} \mathrm{da}{ }^{-1}$ olarak bildirmiştir. Farklı biçim zamanlarının iki fesleğen populasyonundaki etkilerinin araştırıldığı bu çalışmaya ait drog yaprak verimleri daha önceki araştırmaların bulguları arasında yer almıştır. 


\section{Uçucu yağ oranı}

Biçim zamanları bakımından her iki populasyonda 2013, 2014 yılları ve iki yıl üzerinden elde edilmiş ortalama değerler Çizelge 7'de verilmiştir. Çalışmada 2014 yılına ilişskin uçucu yağ ortalaması $(\% 0,78)$ bir önceki yıla göre daha yüksek $(\% 0,72)$ olmuştur. Populasyon x biçim zamanı interaksiyonu önemli bulunmuştur (Çizelge 7). En yüksek uçucu yağ oranına yeşil renkli populasyon \%1,07 değeri ile 3. biçim zamanında sahip olmuştur. En düşük ortalama ise yine yeşil renkli populasyonda altıncı biçim zamanında elde edilmiştir. İlk dört biçim zamanında yeşil renkli populasyon mor renkli populasyona göre değişen düzeylerde daha yüksek uçucu yağ oranlarına sahip olurken son iki biçim zamanında ise bu durumun ters yönde gerçekleştiği gözlenmiştir. $\mathrm{Bu}$ durumun interaksiyona neden olduğu söylenebilir.

Çizelge 6. Fesleğen tiplerinde drog yaprak veriminin $\left(\mathrm{kg} \mathrm{da}^{-1}\right)$ biçimlere ve yıllara göre değişimi (2013-2014).

Table 6. Change of leaf yield $\left(\mathrm{kg} \mathrm{da}^{-1}\right)$ in basil types according to cutting times and years (2013-2014).

\begin{tabular}{|c|c|c|c|c|c|c|c|c|c|}
\hline \multirow{3}{*}{$\begin{array}{l}\text { Biçim } \\
\text { zamanları } \\
\text { Cutting } \\
\text { times }\end{array}$} & \multicolumn{9}{|c|}{ Drog yaprak verimi $\left(\mathrm{kg} \mathrm{da}^{-1}\right) /$ Drug leaf yield $\left(\mathrm{kg} \mathrm{da}^{-1}\right)$} \\
\hline & \multicolumn{3}{|c|}{$\begin{array}{c}\text { 1. Y1l / } 1^{\text {st }} \text { year } \\
2013\end{array}$} & \multicolumn{3}{|c|}{$\begin{array}{l}\text { 2. Y11 / } 2^{\text {nd }} \text { year } \\
2014\end{array}$} & \multicolumn{3}{|c|}{$\begin{array}{c}\text { Genel ortalama / General mean } \\
2013-2014\end{array}$} \\
\hline & $\begin{array}{l}\text { Mor } \\
\text { Purple }\end{array}$ & $\begin{array}{r}\text { Yeşil } \\
\text { Green }\end{array}$ & $\begin{array}{l}\text { Ort. } \\
\text { Mean }\end{array}$ & $\begin{array}{l}\text { Mor } \\
\text { Purple }\end{array}$ & $\begin{array}{l}\text { Yeşil } \\
\text { Green }\end{array}$ & $\begin{array}{l}\text { Ort. } \\
\text { Mean }\end{array}$ & $\begin{array}{c}\text { Mor } \\
\text { Purple }\end{array}$ & $\begin{array}{l}\text { Yeşil } \\
\text { Green }\end{array}$ & $\begin{array}{l}\text { Ort. } \\
\text { Mean }\end{array}$ \\
\hline 1 & $201,50^{\text {bcde }}$ & $201,00^{\text {bcde }}$ & 201,25 & $220,37^{\text {cde }}$ & $172,86^{\mathrm{e}}$ & $196.61^{\mathrm{b}}$ & $210,96^{\mathrm{bcd}}$ & $186,93^{\mathrm{cd}}$ & $198,94^{\mathrm{b}}$ \\
\hline 2 & $262,70^{\mathrm{abcd}}$ & $329,10^{\mathrm{a}}$ & 295,90 & $303,85^{\text {bcd }}$ & $383,97^{\mathrm{ab}}$ & $343,91^{\mathrm{a}}$ & $283,29^{\mathrm{a}}$ & $356,53^{\mathrm{a}}$ & $319,91^{\mathrm{a}}$ \\
\hline 3 & $266,70^{\mathrm{abcd}}$ & $262,00^{\mathrm{a}}$ & 264,35 & $260,00^{\text {cde }}$ & $311,22^{\mathrm{abc}}$ & $285,61^{\mathrm{a}}$ & $263,32^{\mathrm{bc}}$ & $286,27^{\mathrm{ab}}$ & $274,80^{\mathrm{a}}$ \\
\hline 4 & $151,00^{\mathrm{de}}$ & $311,50^{\mathrm{ab}}$ & 231,25 & $267,24^{\text {cde }}$ & $396,13^{\mathrm{ab}}$ & $331,69^{\mathrm{a}}$ & $209,16^{\mathrm{bcd}}$ & $353,85^{\mathrm{a}}$ & $281,51^{\mathrm{a}}$ \\
\hline 5 & $121,80^{\mathrm{e}}$ & $336,50^{\mathrm{a}}$ & 229,15 & $215,77^{\text {cde }}$ & $407,07^{\mathrm{a}}$ & $311,42^{\mathrm{a}}$ & $168,84^{\mathrm{d}}$ & $371,73^{\mathrm{a}}$ & $270,29^{\mathrm{a}}$ \\
\hline 6 & $193,50^{\text {cde }}$ & $327,30^{\mathrm{a}}$ & 260,40 & $244,83^{\text {cde }}$ & $393,57^{\mathrm{ab}}$ & $319,20^{\mathrm{a}}$ & $219,21^{\mathrm{b}}$ & $360,55^{\mathrm{a}}$ & $289,88^{\mathrm{a}}$ \\
\hline $\begin{array}{c}\text { Ort./ } \\
\text { Mean }\end{array}$ & 199,53 & 294,57 & $247,05^{\mathrm{b}}$ & $251,86^{\mathrm{b}}$ & $344,14^{\mathrm{a}}$ & $298,00^{\mathrm{a}}$ & $225,80^{\mathrm{b}}$ & $319,42^{\mathrm{a}}$ & 272,61 \\
\hline LSD & \multicolumn{3}{|c|}{ Populasyon $\mathrm{x}$ biçim zamanı $(\mathrm{P} \leq 0,05): 115,60$} & \multicolumn{3}{|c|}{ 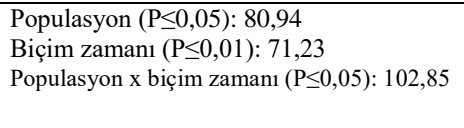 } & \multicolumn{3}{|c|}{$\begin{array}{l}\text { Populasyon ( } \mathrm{P} \leq 0,01): 57,28 \\
\text { Biçim zamanı ( } \mathrm{P} \leq 0,01): 62,70 \\
\text { Populasyon x biçim zamanı ( } \mathrm{p} \leq 0,01): 88,68 \\
\text { Y1l( } \mathrm{P} \leq 0,01): 36,08\end{array}$} \\
\hline CV (\%) & & 19 & & & 10,23 & & & 20,80 & \\
\hline
\end{tabular}

Aynı harfle gösterilen ortalamalar arasında önemli fark $(\mathrm{P} \leq 0,05$ ve $\mathrm{P} \leq 0,01)$ yoktur.

There is no significant difference $(\mathrm{P} \leq 0.05$ and $\mathrm{P} \leq 0.01)$ among means indicated by same letter.

Çizelge 7. Fesleğen tiplerinde uçucu yağ oranın (\%) biçimlere ve yıllara göre değişimi (2013-2014).

Table 7. Change of essential oil content (\%) in basil types according to cutting times and years (2013-2014).

\begin{tabular}{|c|c|c|c|c|c|c|c|c|c|}
\hline \multirow{4}{*}{$\begin{array}{l}\text { Biçim } \\
\text { zamanları } \\
\text { Cutting } \\
\text { times }\end{array}$} & \multicolumn{9}{|c|}{ Uçucu yağ oranı (\%) / Essential oil content (\%) } \\
\hline & \multicolumn{3}{|c|}{$\begin{array}{l}\text { 1. Y1l / } 1^{\text {st }} \text { year } \\
2013\end{array}$} & \multicolumn{3}{|c|}{$\begin{array}{l}\text { 2. Y1l / } 2^{\text {nd }} \text { year } \\
2014\end{array}$} & \multicolumn{3}{|c|}{$\begin{array}{l}\text { Genel ortalama / General mean } \\
\text { 2013-2014 }\end{array}$} \\
\hline & Mor & Yeşil & Ort. & Mor & Yeşil & Ort. & Mor & Yeșil & Ort. \\
\hline & Purple & Green & Mean & Purple & Green & Mean & Purple & Green & Mean \\
\hline 1 & $0,66^{\mathrm{bcd}}$ & $0,92^{\mathrm{ab}}$ & 0,79 & $0,60^{\mathrm{de}}$ & $0,89^{b}$ & $0,75^{b c}$ & $0,64^{\mathrm{def}}$ & $0,90^{\mathrm{ab}}$ & $0,77^{\mathrm{a}}$ \\
\hline 2 & $0,75^{\mathrm{a}-\mathrm{d}}$ & $0,83^{\mathrm{abc}}$ & 0,79 & $0,85^{\mathrm{bc}}$ & $0,86^{\mathrm{b}}$ & $0,86^{\mathrm{ab}}$ & $0,79^{\mathrm{b}-\mathrm{e}}$ & $0,85^{\mathrm{bc}}$ & $0,82^{\mathrm{a}}$ \\
\hline 3 & $0,59^{\text {cde }}$ & $0,95^{\mathrm{a}}$ & 0,74 & $0,65^{\mathrm{de}}$ & $1,13^{\mathrm{a}}$ & $0,89^{\mathrm{a}}$ & $0,62^{\mathrm{ef}}$ & $1,07^{\mathrm{a}}$ & $0,85^{\mathrm{a}}$ \\
\hline 4 & $0,59^{\text {cde }}$ & $0,76^{\mathrm{a}-\mathrm{d}}$ & 0,64 & $0,61^{\mathrm{de}}$ & $0,90^{\mathrm{b}}$ & $0,76^{\mathrm{abc}}$ & $0,59^{\mathrm{ef}}$ & $0,83^{\text {bcd }}$ & $0,71^{\mathrm{ab}}$ \\
\hline 5 & $0,82^{\mathrm{abc}}$ & $0,64^{\mathrm{cd}}$ & 0,73 & $0,88^{\mathrm{b}}$ & $0,67^{\text {cde }}$ & $0,77^{\mathrm{abc}}$ & $0,85^{\mathrm{bc}}$ & $0,65^{\mathrm{c}-\mathrm{f}}$ & $0,75^{\mathrm{a}}$ \\
\hline 6 & $0,69^{\mathrm{cd}}$ & $0,42^{\mathrm{e}}$ & 0,56 & $0,76^{\text {bcd }}$ & $0,52^{\mathrm{e}}$ & $0,64^{\mathrm{c}}$ & $0,72^{\mathrm{b}-\mathrm{e}}$ & $0,47^{\mathrm{f}}$ & $0,60^{\mathrm{b}}$ \\
\hline $\begin{array}{l}\text { Ort./ } \\
\text { Mean }\end{array}$ & 0,68 & 0,75 & $0,72^{b}$ & $0,73^{b}$ & $0,83^{\mathrm{a}}$ & $0,78^{\mathrm{a}}$ & $0,70^{\mathrm{a}}$ & $0,79^{\mathrm{a}}$ & 0,75 \\
\hline LSD & \multicolumn{3}{|c|}{ Populasyon $\mathrm{x}$ biçim zamanı $(\mathrm{P} \leq 0,01): 0,21$} & \multicolumn{3}{|c|}{$\begin{array}{l}\text { Populasyon }(\mathrm{P} \leq 0,01): 0,07 \\
\text { Biçim zamanı }(\mathrm{P} \leq 0,01): 0,14 \\
\text { Populasyon x biçim zamanı }(\mathrm{p} \leq 0,01): 0,19\end{array}$} & \multicolumn{3}{|c|}{$\begin{array}{l}\text { Populasyon }(\mathrm{P} \leq 0,01): 0,11 \\
\text { Biçim zamanı }(\mathrm{P} \leq 0,01): 0,15 \\
\text { Populasyon } \mathrm{x} \text { biçim zamanı }(\mathrm{p} \leq 0,01): 0,21 \\
\text { Y11 }(\mathrm{P} \leq 0,05)=0,06\end{array}$} \\
\hline $\mathrm{CV}(\%)$ & \multicolumn{3}{|c|}{17,2} & \multicolumn{3}{|c|}{22,20} & \multicolumn{3}{|c|}{17,88} \\
\hline
\end{tabular}

Aynı harfle gösterilen ortalamalar arasında önemli fark $(\mathrm{P} \leq 0,05$ ve $\mathrm{P} \leq 0,01)$ yoktur.

There is no significant difference $(\mathrm{P} \leq 0.05$ and $\mathrm{P} \leq 0.01)$ among means indicated by same letter. 
Telci ve ark.(2005), ülkemizde yetiştirilen yerel fesleğen populasyonlarında uçucu yağ oranını $\% 0,38-\% 1,20$ olarak bulmuşlardır. Ekren ve ark. (2009), fesleğen bitkisinde farklı dikim sıklıklarında uçucu yağ oranının $\% 0,36$ ile $\% 1,45$ arasında değiştiğini bildirmişlerdir. NurzynskaWierdak ve ark. (2012) bu oranın \%0,46-\%1,03; Verma ve ark. (2012) ise \%0,18-\%1,14 değerleri arasında değişim gösterdiğini saptamışlardır. Aburigal ve ark. (2016), fesleğen bitkisinde uçucu yağ oranını çiçeklerde $\% 0,29-\% 0,33$, yapraklarda ise $\% 0,32-\% 0,48$ olarak bulmuşlardır.

Bornova'da yürütülen çalışmamızda uçucu yağ oranları Telci ve ark.(2005); Ekren ve ark.(2009); Verma ve ark. (2012) ve Nurzynska-Wierdak ve ark. (2012)'ın sonuçlarına benzer, Aburigal ve ark. (2016)'ından ise yüksek bulunmuştur.

Uçucu yağ taşıyan bitkilerde, bitkinin yetiştiği ekolojik şartlara, gelişme dönemine, uygulanan agronomik işlemlere ve bitkinin genetik yapısına göre uçucu yağ oranının değişim gösterdiği bilinmektedir (Telci, 2005; Nurzynska-Wierdak ve ark., 2012). Kullanılan materyalin farklı bitkisel özelliklere sahip olması nedeniyle, yeşil renkli ve limon kokulu fesleğenlerin 3. biçimde en yüksek uçucu yağ oranına sahip olduğu gözlenmiştir.

\section{Uçucu yağ verimi}

Biçim zamanları bakımından her iki populasyonda 2013, 2014 yılları ve iki yıl üzerinden elde edilmiş ortalama değerler Çizelge 8'de verilmiştir. Çalışmada 2014 yılına ilişkin uçucu yağ verimi ortalamas1 $\left(2,31 \mathrm{l} \mathrm{da}^{-1}\right)$ bir önceki yıla göre daha yüksek $\left(1,761 \mathrm{da}^{-1}\right)$ olmuştur. Populasyon x biçim zamanı interaksiyonu önemli bulunmuştur (Çizelge 8). Dekar başına uçucu yağ verimi bakımından en yüksek ortalama 3,11 litre ile yeşil renkli fesleğenin üçüncü biçim zamanında, en düşük değerler ise mor renkli populasyonun dördüncü ve birinci biçim zamanlarında sırasıyla 1,26 ve 1,32 $1 \mathrm{da}^{-1}$ elde edilmiştir. Yeşil renkli populasyon tüm biçim zamanlarında değişen düzeyde daha yüksek ortalama değerlere sahip olmuştur. Yeşil renkli populasyonun uçucu yağ oranı beşinci ve altıncı biçim zamanlarında diğer populasyondan daha düşük olmasına karşın aynı zamanlarda drog yaprak verimleri daha yüksek olduğu için özellikle beşinci biçim zamanında uçucu yağ verimi mor renkli populasyondan daha yüksek bulunmuştur.

Çizelge 8. Fesleğen tiplerinde uçucu yağ verimlerinin $\left(\mathrm{ka}^{-1}\right)$ biçimlere ve yıllara göre değişimi (2013-2014).

Table 8. Change of essential oil yields $\left(1 \mathrm{ka}^{-1}\right)$ in basil types according to cutting times and years (2013-2014).

\begin{tabular}{|c|c|c|c|c|c|c|c|c|c|}
\hline \multirow{3}{*}{$\begin{array}{l}\text { Biçim } \\
\text { zamanları } \\
\text { Cutting } \\
\text { times }\end{array}$} & \multicolumn{9}{|c|}{ Uçucu yağ verimi $\left(1 \mathrm{da}^{-1}\right) /$ Essential oil yield $\left(1 \mathrm{da}^{-1}\right)$} \\
\hline & \multicolumn{3}{|c|}{$\begin{array}{l}\left.\text { 1. Y1l / } 1^{\text {st }} \text { year }\right) \\
2013\end{array}$} & \multicolumn{3}{|c|}{$\begin{array}{l}\text { 2. Y1l / } 2^{\text {nd }} \text { year) } \\
2014\end{array}$} & \multicolumn{3}{|c|}{$\begin{array}{l}\text { Genel ortalama / General mean } \\
\text { 2013-2014 }\end{array}$} \\
\hline & $\begin{array}{c}\text { Mor } \\
\text { Purple }\end{array}$ & $\begin{array}{l}\text { Yeşil } \\
\text { Green }\end{array}$ & $\begin{array}{l}\text { Ort. } \\
\text { Mean }\end{array}$ & $\begin{array}{c}\text { Mor } \\
\text { Purple }\end{array}$ & $\begin{array}{l}\text { Yeşil } \\
\text { Green }\end{array}$ & $\begin{array}{l}\text { Ort. } \\
\text { Mean }\end{array}$ & $\begin{array}{l}\text { Mor } \\
\text { Purple }\end{array}$ & $\begin{array}{l}\text { Yeşil } \\
\text { Green }\end{array}$ & $\begin{array}{l}\text { Ort. } \\
\text { Mean }\end{array}$ \\
\hline 1 & 1,33 & 1,85 & 1,59 & $1,32^{\mathrm{f}}$ & $1,54^{\mathrm{f}}$ & $1,43^{\mathrm{d}}$ & $1,32^{\mathrm{e}}$ & $1,71^{\text {cde }}$ & $1,52^{\mathrm{c}}$ \\
\hline 2 & 1,97 & 2,73 & 2,35 & $2,58^{\text {cde }}$ & $3,30^{\mathrm{abc}}$ & $2,94^{\mathrm{a}}$ & $2,20^{\mathrm{bcd}}$ & $3,02^{\mathrm{ab}}$ & $2,61^{\mathrm{a}}$ \\
\hline 3 & 1,57 & 2,49 & 2,03 & $1,68^{\mathrm{ef}}$ & $3,52^{\mathrm{ab}}$ & $2,60^{\mathrm{ab}}$ & $1,56^{\mathrm{de}}$ & $3,11^{\mathrm{a}}$ & $2,34^{\mathrm{ab}}$ \\
\hline 4 & 0,89 & 2,37 & 1,63 & $1,63^{\mathrm{f}}$ & $3,57^{\mathrm{a}}$ & $2,60^{\mathrm{ab}}$ & $1,26^{\mathrm{e}}$ & $2,97^{\mathrm{ab}}$ & $2,11^{\mathrm{abc}}$ \\
\hline 5 & 1,00 & 2,15 & 1,58 & $1,90^{\mathrm{def}}$ & $2,73^{\mathrm{a}-\mathrm{d}}$ & $2,31^{\mathrm{bc}}$ & $1,43^{\mathrm{de}}$ & $2,46^{\mathrm{abc}}$ & $1,95^{\mathrm{bc}}$ \\
\hline 6 & 1,34 & 1,37 & 1,35 & $1,86^{\mathrm{def}}$ & $2,05^{\mathrm{def}}$ & $1,95^{\mathrm{cd}}$ & $1,59^{\mathrm{de}}$ & $1,70^{\text {cde }}$ & $1,64^{\mathrm{c}}$ \\
\hline $\begin{array}{l}\text { Ort./ } \\
\text { Mean }\end{array}$ & $1,35^{\mathrm{b}}$ & $2,16^{\mathrm{a}}$ & $1,76^{\mathrm{b}}$ & $1,83^{\mathrm{b}}$ & $2,78^{\mathrm{a}}$ & $2,31^{\mathrm{a}}$ & $1,56^{\mathrm{b}}$ & $2,49^{\mathrm{a}}$ & 2,02 \\
\hline LSD & \multicolumn{3}{|c|}{ Populasyon ( $\mathrm{P} \leq 0,01): 0,36$} & \multicolumn{3}{|c|}{$\begin{array}{l}\text { Populasyon }(\mathrm{P} \leq 0,05): 0,77 \\
\text { Biçim zamanı }(\mathrm{P} \leq 0,01): 0,604 \\
\text { Populasyon } \mathrm{x} \text { biçim zamanı }(\mathrm{p} \leq 0,01): 0,89\end{array}$} & \multicolumn{3}{|c|}{$\begin{array}{l}\text { Populasyon }(\mathrm{P} \leq 0,01): 0,49 \\
\text { Biçim zamanı }(\mathrm{P} \leq 0,01): 0,61 \\
\text { Populasyon x biçim zamanı }(\mathrm{p} \leq 0,01): 0,86 \\
\mathrm{Y} 1(\mathrm{P} \leq 0,01): 0,34\end{array}$} \\
\hline $\mathrm{CV}(\%)$ & \multicolumn{3}{|c|}{17,2} & \multicolumn{3}{|c|}{22,20} & \multicolumn{3}{|c|}{27,20} \\
\hline
\end{tabular}

Aynı harfle gösterilen ortalamalar arasında önemli fark $(\mathrm{P} \leq 0,05$ ve $\mathrm{P} \leq 0,01)$ yoktur.

There is no significant difference $(\mathrm{P} \leq 0.05$ and $\mathrm{P} \leq 0.01)$ among means indicated by same letter. 
Aslan (2014), Aydın ekolojik koşullarında, yedi farklı fesleğen genotipini incelediği çalışmasında iki biçim zamanı ortalaması olarak uçucu yağ verimini $12,57 \mathrm{lda}^{-1}$ olarak saptamıştır. Araştırıcının bulduğu değerin bizim bulgumuzdan $\left(2,021 \mathrm{da}^{-1}\right)$ yüksek olmasının sebebi bitkide uçucu yağ miktarının en yüksek olması beklenen çiçeklenme sürecinde biçim yapılmış olmasıdır.

\section{SONUÇ}

İki y1l süre ile iki farklı fesleğen populasyonunda yürütülen araştırma sonuçları genel olarak değerlendirildiğinde, en yüksek ortalama değerlerin yeşil renkli fesleğende ve çoğunlukla 2., 3. ve 4. biçim zamanlarında elde edildiği görülmüştür. Ancak populasyon $\mathrm{x}$ biçim zamanı interaksiyonunun tüm özellikler için önemli olması nedeniyle bu üstünlük biçim zamanlarına göre değişiklik göstermiştir. Fesleğen bitkisinde baharat amaçlı kullanılan kısım yapraklar olduğu için, drog yaprak

\section{LITERATÜR LİSTESI}

Aburigal, Y. A. A., N. B. Hamza, I. H. Hussein, E. Y. Elmogtaba, T. H. Osman, F. I. Ali, and A. A. M. Siribel. 2016. Variability in content and chemical constituents of essential oil of sweet basil (Ocimum basilicum L.) obtained from aerial plant parts. Advances in Bioscience and Biotechnology 7: 183-187.

Açıkgöz, N., Akkaş, M. E. Özcan ve K. Moghaddam. A.F. 1994. PC'ler için veritabanı esaslı türkçe istatistik paketi: TARIST, Tarla Bitkileri Kongresi. 25-29 Nisan 1994. E.Ü.Z.F. Bornova/İzmir.

Akgül, A. 1993. Baharat Bilimi ve Teknolojisi. Gida Teknolojisi Derneği Yayınları No: 15. s. 451.

Aslan, D. F. 2014. Farklı reyhan (Ocimum basilicum L.) populasyonlerinde ontogenetik ve morfogenetik varyabilitenin belirlenmesi. Yüksek lisans tezi. Adnan Menderes Üniversitesi Fen Bilimleri Enstitüsü. s.106.

Ceylan, A. 1997. Tıbbi Bitkiler-II (Uçucu Yağ Bitkileri). s.306. E.Ü.Z.F. Yayınları No: 481. Bornova, İzmir.

Chrpova, D., L. Kourimska, M. H . Gordon, V. Hermanova, I. Roubickova, and J. Pánek. 2010. Antioxidant activity of selected phenols and herbs used in diets for medical conditions. Czech J. Food Sci. 28 (4): 317-325.

Ekren, S., Ç. Sönmez, S. Sancaktaroğlu ve E. Bayram. 2009. Farklı dikim sıklıklarının fesleğen (Ocimum basilicum L.) bitkisinin verim ve kalite özellikleri üzerine etkisi. Ege Üniv. Ziraat Fak. Derg. 46 (3): 165-173. verimi çalışmamız için dikkate alınması gereken önemli özelliklerden biridir. Drog yaprak verimleri bakımından en yüksek değerler yeşil renkli fesleğende 2., 4., 5. ve 6 . biçim zamanından elde edilmiştir. Kalite kriterlerinden biri olan uçucu yağ veriminde ise en yüksek değerlere 2., 3. ve 4 . biçim zamanlarında ulaşılmıştır. Drog yaprak verimi, drog herba veriminin bir bileşenidir. Drog herba verimi 2. ve 4. biçim zamanında yüksek olup bunlarda drog yaprak veriminin drog herba verimine oranı sirasiyla $\% 70,50$ ve $\% 68,10$ olup 3 . biçim zamanında ise bu oran daha düşüktür $(\% 55,90)$. Sözü edilen olguların 1şı̆̆ında, çalışmanın yürütüldüğü kıyı Ege Bölgesi koşullarında fesleğen bitkisinde yüksek drog yaprak ve uçucu yağ verimlerinin elde edilebilmesi için ticari üretimde yeşil renkli fesleğenin kullanılması ve en uygun biçim zamanı olarak da 2. veya 4. zamanın tercih edilmesi gerektiği sonucuna varılabilir.

Ekren, S., Ç. Sönmez, E. Özçakal, Y. S. K. Kurttaş, E. Bayram ve H. Gürgülü. 2012. The effect of different irrigation water levels on yield and quality characteristics of purple basil (Ocimum basilicum L.). Agricultural Water Management 109: 155-161.

Erşahin, L. 2006. Diyarbakır ekolojik koşullarında yetiștirilen fesleğen (Ocimum basilicum L.) populasyonlarının agronomik ve kalite özellikleri. Yüksek Lisans Tezi. C. Ü. Fen Bil. Enst. Adana.

Hussain, A. I., F. Anwar, S. T. H. Sherazi, and R. Przybylsk. 2008. Chemical composition, antioxidant and antimicrobial activities of basil (Ocimum basilicum L.) essential oils depends on seasonal variations. Food Chem. 108: 986-995.

Koba, K., P. W. Poutouli, C. Raynaud, J. P. Chaumont and K. Sanda. 2009. Chemical composition and antimicrobial properties of different basil essential oils chemotypes from Togo. Bangladesh J. Pharmacol. 4: 1-8.

Nurzyńska-Wierdak, R., A. Bogucka-Kocka, and B. Borowski. 2012. Changes in the chemical composition of the essential oil of sweet basil (Ocimum basilicum L.) depending on the plant growth stage. Chemija 23 (3): 216-222.

Sokovic, M., P. D. Marin, D. Brkic, and L. J. L. D. van Griensven. 2007. Chemical composition and antibacterial activity of essential oils of ten aromatic plants against human pathogenic bacteria. Food 1 (1): 220-226. 
C.. SÖNMEZ, A. Ö. ȘIMSSEK SOYSAL, A. YILDIRIM, F. BERBEROĞLU, E. BAYRAM: FARKLI BICÇIM ZAMANLARININ YEŞiL VE MOR FESLEĞEN (Ocimum basilicum L.) TIPLERINDE BAZI VERIM VE KALITE ÖZELLIKLERİ ÜZERINE ETKISI

Telci, İ., E. Bayram, G. Yılmaz ve A. B. Avc1. 2005 Türkiye'de kültürü yapılan yerel fesleğen (Ocimum spp.) populasyonlerinin morfolojik, agronomik ve teknolojik özelliklerinin karakterizasyonu ve üstün bitkilerin seleksiyonu (Sonuç Raporu). TOGTAG3102 No'lu Proje. TÜBİTAK.

Verma, R. S., R. C. Padaliab, and A. Chauhan. 2012.Variation in the volatile terpenoids of two industrially important basil (Ocimum basilicum L.) cultivars during plant ontogeny in two different cropping seasons from India. J. Sci. Food Agric. 92: 626-631.
Wichtl, M. 1971. Die pharmakogostich-chemisehe Untersuchung und Wertbestimmung von Drogen und galenischen Präparaten. Methoden der Analyse in der Chemie Band 12. Frankfurt and Main. 